\title{
Configurações
}

Revista de sociologia

$9 \mid 2012$

Trabalho e género: vidas precárias, percursos e acção colectiva

\section{Redes e reconfiguração organizacional: o contributo de Norbert Elias}

Networks and organizational reconfiguration: the contribution of Norbert Elias

Réseaux et reconfiguration organisationnelle: la contribution de Norbert Elias

Helena Areias e Ana Paula Marques

\section{(2) OpenEdition \\ Journals}

\section{Edição electrónica}

URL: http://journals.openedition.org/configuracoes/1101

DOI: 10.4000/configuracoes. 1101

ISSN: 2182-7419

\section{Editora}

Centro de Investigação em Ciências Sociais

\section{Edição impressa}

Data de publição: 30 Junho 2012

Paginação: 37-56

ISSN: 1646-5075

\section{Refêrencia eletrónica}

Helena Areias e Ana Paula Marques, « Redes e reconfiguração organizacional: o contributo de Norbert Elias », Configurações [Online], 9 | 2012, posto online no dia 27 novembro 2013, consultado o 30 abril 2019. URL : http://journals.openedition.org/configuracoes/1101; DOI : 10.4000/configuracoes. 1101

Este documento foi criado de forma automática no dia 30 Abril 2019.

(c) CICS 


\title{
Redes e reconfiguração organizacional: o contributo de Norbert Elias
}

\author{
Networks and organizational reconfiguration: the contribution of Norbert Elias \\ Réseaux et reconfiguration organisationnelle: la contribution de Norbert Elias
}

Helena Areias and Ana Paula Marques

\section{Introdução}

1 Vive -se uma época de profundas transformações acompanhada pela procura de novas arquitecturas e modelos organizacionais como resultado de desadequação e desajustamento dos paradigmas tradicionalmente mais influentes sobre a gestão e organização às "novas realidades" societais. Esta crescente necessidade de renovação e experimentação de abordagens mais consentâneas com a complexidade, a mudança, a incerteza e o risco em que se vive nas sociedades contemporâneas tem conduzido vários autores à descoberta e apresentação de designações adequadas para a explicação e a compreensão dos factos sociais constitutivos de uma "nova" era de redes. As expressões de "idade da rede" (Lipnack e Stamps, 1994), "sociedade em rede" (Castells, 1996) e "sociedade de redes" (Prigogine, 2000) são ilustrativas dessas mudanças em curso.

2 A importância das redes organizacionais é enunciada nas palavras de Capra quando afirma que (2002: 267) “(...) na Era da informação na qual vivemos, as funções e processos sociais organizam -se cada vez mais em torno de redes. Quer se trate das grandes empresas do mercado financeiro, dos meios de comunicação ou das novas ONGs globais, constatamos que a organização em rede tornou -se um fenómeno social importante e uma fonte crítica de poder". Na mesma linha, Dabas (2001) reitera que no campo da sociologia e da teoria das organizações surgem experiências que visam implementar a modalidade de "organização em rede", em detrimento da abordagem administrativa clássica. Estes novos paradigmas organizacionais apresentam -se distintos das burocracias weberianas modernas, já que são diversas as modalidades e os meios que podem sustentar a 
emergência de redes organizacionais. Estas apresentam como traços centrais dimensões de não linearidade, descentralização, flexibilidade e auto-organização e pressupõem relações horizontais de cooperação.

3 A atenção dada a este fenómeno atingiu uma dimensão tal que Miles e Snow (1992:53) observavam que estaríamos num momento de "revolução no meio organizacional". De facto, dos paradigmas organizacionais emergentes, as formas de organização em rede é considerada, por muitos autores (Costa, et al., 2003), a morfologia característica das sociedades contemporâneas. Na verdade, "hoje o cenário exibe um caleidoscópio emaranhado de redes nos mais variados âmbitos, territórios e campos de acção, nível local, microrregional, estadual, nacional e internacional, com os nomes mais diversos (entre outros, 'fórum', 'articulação', 'movimento', 'colectivo') e desenhos organizacionais diferentes" (idem, 2003:12).

4 A este processo de proliferação de redes está associada uma multiplicidade de factores como a globalização económica, que altera os processos produtivos, e os modelos de organização administrativa face à necessidade de uma maior flexibilização e interdependência. Para além destas questões, emergem igualmente mudanças societais visíveis nas alterações do papel do Estado nas suas relações com as organizações e a sociedade em geral, impondo novos modelos de gestão que comportam a interacção de estruturas descentralizadas, de acções inovadoras e de parcerias entre organizações do Estado, da sociedade civil e do mercado, entre outras. Por sua vez, neste quadro mais amplo de proliferação de redes, são relevantes, também, as mudanças nas relações de trabalho e emprego, nos quadros normativos, interactivos e de orientações valorativas e simbólicas que caracterizam os actores sociais nos diversos contextos organizacionais (e.g. responsabilidade, participação, autonomia, desenvolvimento pessoal e profissional complementam a argumentação (Marques, 2008, 2007).

5 Para este processo de reconfiguração organizacional, convoca-se, neste artigo, o pensamento Eliano pela actualidade e evidência da sua reflexão, com enorme valor estratégico e heurístico, para a compreensão de um mundo complexo, paradoxal, que inclui dimensões de incerteza e risco. Para Norbert Elias (2004), as relações sociais são explicadas como uma teia de complexas interdependências criada pelas interacções humanas entre "eu" e o "tu", entre o "nós" e o "eles", entre indivíduos diferentes e/ou iguais, em constante dinâmica geradora de fenómenos reticulares. Esta perspectiva apresenta as redes organizacionais, ou estruturas policêntricas, como constituintes da morfologia social das sociedades contemporâneas.

6 As redes organizacionais constituem um fenómeno recente e em rápida difusão nas diferentes áreas e sectores, desde o produtivo e as redes empresariais, o social e as redes de políticas e movimentos sociais e o psicológico e as redes de apoio psicológico. $\mathrm{Na}$ verdade, observa -se um crescente experimentalismo organizacional na procura de abordagens inovadoras com maior potencial de adequação ao ambiente de turbulência, complexidade e de mudança, através da criação de modelos organizacionais mais flexíveis e conciliáveis com processos de auto-transformação contínua (Nogueira, 2004).

70 argumento central deste artigo desenvolve -se primeiro através da revisitação do pensamento de Elias para, em seguida, refl ectir sobre o conhecimento acumulado das formas de organização em rede, de modo a se ensaiar um pensamento crítico para lá da lógica da racionalidade linear, causal e determinista. 


\section{As formas de organização em rede por Norbert Elias}

8 Face ao vasto contributo da obra de Norbert Elias para a sociologia em geral, iremos revisitar o pensamento de Elias pela evidência de uma reflexão de enorme valor estratégico e heurístico centrado na ideia de complexidade, interdependência e redes constitutivas da actual morfologia das organizações e sociedade em geral. $\mathrm{Na}$ senda de Elias (2004), poder-se-á perspectivar que, em grande medida, as respostas às transformações sociais se encontram nas interacções sociais desencadeadoras de mudanças estruturais. É desta base que partimos para conferir uma significação aos fenómenos reticulares na contemporaneidade, ou seja, as formas de organização em rede.

\subsection{Uma teoria social do processo}

O pensamento de Norbert Elias ${ }^{1}$ parte de uma base empírica para estudar as relações humanas de forma processual. No enquadramento das teorias gerais da sociologia, Elias sustenta uma visão: $i$ ) universalista, que visa ultrapassar a dicotomia de abordagens centradas no sujeito/ objecto, no indivíduo/ sociedade; ii) interdisciplinar, pelo esforço de superação de fronteiras entre áreas disciplinares; iii) e interdependente, ao evidenciar o entrelaçamento de relações entre pessoas e a formação de constelações distintas conceptualizadas como "configuração" em contraposição a homo clausus (Elias, 2004). A noção de homus clausus ${ }^{2}$, que o autor tanto rejeitava, pode ser entendida como a dualidade entre indivíduo e sociedade, sujeito e objecto, que significa o indivíduo enquanto ser atomizado completamente livre e autónomo em relação ao social. Por "configuração", Elias pretendeu expressar a ideia de que os seres humanos são interdependentes e apenas podem ser entendidos como tal; as suas vidas desenrolam-se e são moldadas por processos dinâmicos próprios em constante fluxo, passando por mudanças de ordens diversas. Por outras palavras, configuração pode designar -se pelas redes formadas por seres humanos interdependentes (Landini, 2005).

O conceito de configuração pode aplicar -se onde quer que se formem conexões e teias de interdependência humana, já que expressa a ideia de um ser humano com abertura e algum grau de autonomia relativa (mas nunca absoluta) em relação aos outros homens. Para Elias, qualquer ser humano "está, de facto, durante toda a vida, fundamentalmente orientado para os outros homens e dependente deles. O tecido das interdependências entre homens é aquilo que os liga uns aos outros. São elas que constituem o núcleo daquilo que se designa aqui como figuração - uma figuração de homens orientados uns para os outros" (Elias, 1989:45)3.

11 Elias procurou conceber uma teoria de desenvolvimento humano baseada numa visão dinâmica dos processos sociais através de uma dimensão do saber da história na abordagem dos problemas sociais. Na sua obra de referência, $O$ Processo Civilizacional (1989:14), o autor afirma: "Ao trabalhar este livro, pareceu-me absolutamente evidente que com ele se lançariam as bases para uma teoria sociológica, não dogmática e fundamentada empiricamente, dos processos sociais em geral e da evolução social em particular". Pode-se afirmar que Elias foi responsável pelo desenvolvimento de uma teoria social inovadora, que contribuiu para alargar o campo dos estudos sociológicos voltados para a compreensão dos processos de interacção humana no âmbito da sociedade. Com 
efeito, o autor propôs -se alargar a compreensão dos processos humanos e sociais para adquirir um conhecimento mais sólido acerca dos mesmos.

Assim, a teoria sociológica formulada por Elias apresenta -se como uma abordagem de carácter crítico, cujos conceitos centrais foram construídos a partir da identifi cação de defi ciências e limitações de perspectivas teóricas clássicas pelas ciências sociais, mais concretamente pelo estruturo- funcionalismo. Com efeito, o autor refuta instrumentos conceptuais como "estrutura" e "função" num quadro de referência estático das teorias estruturais dominantes - à época - pois, para ele, "comportam o cunho desse estilo específico de pensamento que tudo reduz a estados" (1989:19) e a repouso no sentido em que não se inclui a dinâmica constitutiva do social. Trata-se de uma crítica à redução processual, isto é, à tendência de reduzir conceitualmente processos a algo de estático, sem movimento, nem acção.

Os teóricos da perspectiva funcionalista e estruturalista tendem a identificar as estruturas sociais a atributos constrangedores com grande influência sobre o comportamento dos indivíduos. Introduzindo uma inflexão nesse pensamento, Elias refuta qualquer concepção de que as forças coercivas têm um carácter objectivo acima e para além dos indivíduos. A relação entre indivíduo ("ego") e estrutura social ("sistema social") poderá ser analisada e concebida como um processo que, embora sendo coisas diferentes, são inseparáveis. A análise recai sobre as teias da interdependência humanas que formam as configurações sociais, já que "o devir das estruturas da personalidade e da sociedade efectiva-se na indissolúvel relação entre ambas" (Elias 1989: 18). As ligações pessoais a que Elias se refere dizem respeito não só às relações interpessoais, como também às ligações emocionais, considerando -as como "agentes unificadoras de toda a sociedade" (Elias 1989:150).

14 Por conseguinte, a teoria sociológica assim formulada concebe a relação entre "indivíduo" e "sociedade" de uma outra forma, não aceitando qualquer visão "totalizadora" e/ ou "individualista" dos processos sociais. Ao se focalizar na análise das inter-relações entre os indivíduos, o autor rejeita a ideia de polarização conceptual, já que é um reflexo muito nítido de vários ideais sociais e sistemas de crenças: “por um lado, há um sistema de crenças cujos adeptos atribuem o mais alto valor à 'sociedade'; por outro, há um sistema de crenças cujos adeptos atribuem o mais alto valor ao "indivíduo"' (1989:14). Resultam daqui dois objectos que existem separadamente, forçando a ideia do "eu" como estando numa caixa fechada (homo clausus), tal como atrás se referiu.

Ao rejeitar uma lógica inscrita num raciocínio dicotómico de "ou/ ou", o autor propõe uma definição de sociologia, afirmando que esta "trata dos problemas da sociedade e a sociedade é formada por nós e pelos outros" (Elias, 2008:13). A questão fulcral é, portanto, a interdependência para a definição de configurações sociais. A centralidade do pensamento de Elias, que passamos abaixo a aprofundar, baseia -se sobretudo nas redes de interdependência dos indivíduos, na medida em que "o indivíduo está ligado aos outros por um fenómeno de dependência recíproca” (2001: 56).

\subsection{0 "Eu e o Nós" nos processos de configuração}

Reflectindo sobre a relação entre indivíduo e sociedade, Elias propõe -se romper com "o uso mais antigo e corrente destes conceitos" (2004: 16). Não os aceita enquanto axiomas sem questionamento. A tentativa do autor vai no sentido de não os vermos como "par antagónico, mas teremos que nos esforçar (...) por um novo modelo funcional onde os 
homens individuais estejam tanto no bem, como no mal, interligados, como pluralidade, ou seja, como sociedade" (Ibidem). A separação pode até existir numa produção histórica e de distinção conceptual para facilitar o estudo sociológico, mas para o pensador, em geral, e para o sociólogo, em particular, indivíduo e sociedade não são separáveis.

Para tal, Elias desenvolve um pensamento baseado numa sociologia histórica de conceitos e esclarece as mudanças na abordagem da relação entre indivíduo e sociedade. Para a compreender é imprescindível atender às mudanças que se verificaram quer nos indivíduos ("mudanças da auto-experiência"), quer nas sociedades ("mudanças do hábito social dos indivíduos") (Elias, 2004:18). A conceptualização complexifica -se através do conceito de "Equilíbrio do Nós/Eu", revelando que a relação entre a identidade do "Eu" e do "Nós" é mutável e que sofre transformações singulares (Ibidem). A questão está em saber o que estrutura o conjunto, isto é, descobrir qual o sistema de relações que liga os indivíduos.

Outro contributo de fundo do autor consiste em reflectir sobre os processos que constituem a sociedade. A sua proposta ancora -se a partir de campos opostos. Um deles assente na determinação de configurações histórico-sociais por indivíduos ou grupos de indivíduos/ entidades (os heróis, as correntes, as instituições). Neste campo são centrais as ideias de projecto e de criação individual, não se esclarecendo, contudo, a passagem de acções ou fins individuais para as configurações sociais. O outro campo baseia-se na determinação orgânica supra-individual ou espírito supra-individual comum (espírito universal, segundo Hegel), sendo aqui centrais os "estilos ou as formas culturais ou as formas de economia e instituições" (Elias, 2004:23).

19 Igualmente, Elias procura mostrar as conexões entre linguagem, práticas sociais, história e biologia. Trata -se de uma abordagem original e ousada tanto para a sociologia clássica, como para a contemporânea ${ }^{4}$. 0 desafio reside em se conseguir criar um modelo de pensamento e uma visão global que tornem inteligíveis a realidade. Isto é, que permitam compreender como os seres humanos em conjunto formam uma sociedade que não foi pretendida, nem planeada por nenhum dos seres humanos que a constituem e cuja história não foi previamente definida pelos indivíduos que a compõem, nem por uma qualquer entidade supra-individual (natural ou religiosa). Para a compreensão de modelos que assumam a relação entre indivíduo e sociedade, Elias recua ao clássico Aristóteles que relaciona as pedras e uma casa. Trata -se de um modelo simples - o da relação entre as pedras e uma casa - que demonstra como muitos elementos singulares formam um conjunto, cuja constituição não pode ser compreendida a partir de cada elemento constituinte. A estrutura não pode ser compreendida se isolarmos cada elemento, nem pode ser entendida se abordada partindo da ideia de ser uma soma como se fosse um montão de pedras.

Também a teoria configuracional constitui uma importante referência teórica no pensamento de Elias. Com efeito, a teoria configuracional assume que o todo não é igual à soma das partes, já que possui uma regularidade própria que não é dedutível a partir dos elementos constituintes, sendo atribuída importância à relação entre os elementos. Porém, será que existe um modelo de "convivência humana" harmonioso (Elias, 2004), isto é, onde as necessidades e os desejos individuais se encontrem satisfeitas e a estrutura social não seja conflituosa? Parece existir nas configurações sociais um fosso intransponível entre as necessidades e desejos individuais e as condições necessárias à vida em sociedade. Este fosso condiciona o modo como pensamos a relação entre indivíduo e sociedade. Para o ultrapassar impõe -se estabelecer uma ruptura com este 
antagonismo. Ao fazê-lo, constatamos que o indivíduo e a sociedade são as faces de uma mesma moeda, ou seja, "têm simplesmente uma existência - o indivíduo em sociedade com outros, a sociedade como sociedade de indivíduos" (Elias, 2004:28).

21 Para Elias, as sociedades caracterizam -se pela existência de "contradições, tensões e explosões" (2004:30), sendo a sua constituição não evidente, nem a sua estrutura tangível. As sociedades são abertas e, portanto, ilimitadas. A existência de uma "ordem oculta" de redes de relações de interdependências (afectivas, laborais, entre outras), embora sejam "elásticas, variáveis e transformáveis", não deixam de ser menos reais, nem menos fortes (2004:34).

Para se estudar a sociedade é necessário analisar o modo como se estruturam as relações entre os indivíduos e nunca os indivíduos per si, isoladamente. É necessário atender às funções sociais e às suas relações; atender aos "fenómenos de interdependências" (Elias, 2004:42), isto é, a toda a rede de relações que se estabelece ao longo da vida dos indivíduos (desde crianças a adultos). Os comportamentos, os pensamentos, as convicções, os afectos e as necessidades resultam das relações que o indivíduo estabelece com os outros. Assim, a personalidade, o "si mesmo", só pode ser compreendido a partir "do todo da teia", que permite revelar "o tecido das relações do qual ele sai e para onde entra" (Elias, 2004:52). A individualidade é determinada pela história e pela estrutura da teia humana da qual constitui um ponto de união. A singularidade individual resulta das transformações decorrentes das relações que se estabelecem com os outros, através e pelas quais estes se modelam e remodelam em permanente interdependência - "fenómeno de entrelaçamento" (Elias, 2004:43). Por conseguinte, o estudo sociológico das teias de interdependência indica que as coerções ou forças sociais têm origem na própria teia de interdependência formada pelos indivíduos.

Enquanto o crescimento físico se processa segundo um mecanismo natural, a diferenciação rigorosa e decisiva das funções psíquicas é determinada pelo entrelaçamento, isto é, pela teia de relações humanas. O mesmo se verifica com os impulsos e afectos. Estas duas partes do organismo humano, a física ou o "corpo" (órgãos e funções necessários à sobrevivência e reprodução) e a psíquica ou a "alma" (relação e auto -regulação das relações com os outros) são interdependentes. Este facto explica a dependência do homem face à sociedade, ou seja, de o homem ser um ser social.

Uma das características da auto -regulação psíquica é a plasticidade e a maleabilidade que se traduzem numa elevada mutabilidade e adaptabilidade a diferentes tipos de relações (Elias, 2004:55). Daí a diversidade de estruturas de relações humanas que se encontra liberta de determinismos decorrentes de automatismos herdados. Simultaneamente, constata -se uma complementaridade e interdependência entre as estruturas da psique, da sociedade e da história humana (Elias, 2004:56 -7). Nessa perspectiva, a relação entre o indivíduo e as estruturas sociais deve ser analisada e concebida como um processo. Dito de outra forma, "estruturas sociais" e "indivíduo" (ou "sistema social" e "ego") são distintos, mas inseparáveis, cuja análise deve recair sobre as teias de interdependência humanas que formam as configurações sociais.

Ao se preocupar em explicar as motivações que levam os indivíduos a construírem teias e cadeias de interdependência, Elias refere que uma parte da teia de interdependência tem origem nas necessidades biológicas dos seres humanos. Estes, desde os primeiros momentos da sua vida, precisam dos cuidados e de atenção dos seus pais. Contudo, uma grande parte das teias de interdependência advém de necessidades recíprocas, socialmente geradas, tais como a divisão do trabalho. Os factos e os acontecimentos 
originam -se a partir de um fluxo contínuo da acção individual, imersa em contextos de interacção social nas teias de interdependência. Por isso, para Elias (2008:151), uma das "maiores lacunas das teorias mais antigas da sociologia contemporânea é o facto de investigarem essencialmente as perspectivas sociais do 'eles', quase não se servindo de instrumentos conceptuais rigorosos para investigar a perspectiva de 'eu e nós”'. No encalço de autor é necessário propor uma outra forma de olhar e fazer ciência social.

\subsection{Esforço de reconceptualização da ciência}

De um modo geral, Elias é peremptório quando afirma que: "os sociólogos estão acostumados a encarar as ligações humanas essencialmente sob a perspectiva de 'eles" (Elias, 2008:150). Para inverter esse modo de pensar, o autor procura uma visão mais completa da teoria sociológica onde se incluam as interdependências pessoais e as ligações emocionais entre as pessoas, considerando-as como agentes co -estruturantes de toda a sociedade.

$\mathrm{Na}$ perspectiva de Elias, a abordagem sociológica mais antiga e contemporânea concebe o "Eu" no centro e as configurações como a família, a escola, a indústria e o Estado, em círculos fechados e sem relação à volta do "Eu". No fundo, o ego aparece rodeado de estruturas sociais, estando em cima e acima do ego individual. o conceito de sociedade é encarado de igual modo. Tal visão distorce a compreensão da nossa própria vida em sociedade e encoraja a ideia de que a sociedade é constituída por estruturas que são exteriores aos indivíduos e que os indivíduos são simultaneamente rodeados e separados da sociedade por uma barreira invisível.

O autor propõe uma alteração nesta visão substituindo -a por outra, por ele considerada mais realista, a das pessoas que, através das suas disposições básicas, são orientadas umas para as outras e unidas umas às outras das mais diversas formas. As pessoas "constituem teias de interdependência ou configurações de muitos tipos, tais como famílias, escolas, cidades, estratos sociais ou estados" (Elias, 2008:15). Ou seja, "Cidades e aldeias, universidades e fábricas, estados e classes, famílias e grupos operacionais, todos eles constituem uma rede de indivíduos. Cada um de nós pertence a esses indivíduos" (Elias, 2008:16). Quando nos referimos às estruturas, utilizamos pronomes possessivos como, por exemplo, a "minha" aldeia, a universidade "dele", a "vossa" escola, como se essas mesmas estruturas existissem não só acima e para além de nós mesmos, mas também acima e para além de qualquer pessoa. Este é um tipo de pensamento dicotómico, o que opõe "eu" ou "os indivíduos particulares" de um lado, e, do outro lado, a estrutura social, o meio que me circunda e aos outros "eus".

A maneira como formamos as palavras e os conceitos reforça a tendência do nosso pensamento para "coisificar", ou seja, para desumanizar as estruturas sociais. Esta concepção decorre de modos de pensar e de falar primeiramente desenvolvidos e testados na investigação das relações naturais em física e em química, depois transpostos para a investigação das relações sociais entre os indivíduos. Muitas palavras e conceitos derivam basicamente da interpretação de factos naturais transferidos indevidamente para a interpretação de fenómenos humanos e sociais (Ibidem).

Ainda numa perspectiva histórica, o autor considera que se procurou alargar a compreensão dos processos humanos e sociais, tentando adquirir -se uma base crescente de conhecimentos mais sólidos acerca desses processos (uma das tarefas fundamentais da sociologia). Aí confrontamo-nos com uma tarefa de emancipação que não se apresenta 
fácil. Por um lado, encontramos modelos de um tipo ingenuamente egocêntrico, como o modelo mágico -mítico e, por outro, modelos "tirados" das ciências naturais. Na óptica de Elias (2008), usamos substantivos nas ciências sociais e no dia -a -dia como se nos referíssemos a objectos visíveis e tangíveis no tempo e no espaço, existindo independentemente das pessoas, e impedindo que se desenvolva um modo mais autónomo de falar e de pensar adequado às especificidades das configurações humanas. Daí, ainda não nos ser possível investigar sem este tipo de vocabulário de estrutura conceptual. Necessitamos de uma grande inovação linguística e conceptual para se atingirem certas transformações sociais, que só se podem mesmo efectuar quando houver um desenvolvimento que abarque várias gerações. Na verdade, "torna-se necessária uma reorganização da percepção e do pensamento de todas as muitas pessoas interdependentes numa sociedade. Se uma grande maioria tiver que reaprender a repensar tudo isto, tendo que se acostumar a todo um complexo de conceitos novos - ou conceitos velhos com um novo significado - então torna-se necessário um período de duas ou três gerações por vezes mesmo de muitas mais (...) (Elias, 2008: 21). Esta passagem é clarificadora da dificuldade e morosidade de uma reorientação da linguagem social e do pensamento, dando -nos uma ideia do tipo de forças que as pessoas exercem umas sobre as outras.

31 Na verdade, a nossa linguagem e pensamento são marcadas e expressas por palavras e conceitos como "necessidade causal", "determinismo", "leis científicas", entre outros do mesmo tipo, denotando modelos derivados de experiência prática no campo das ciências naturais, da física e da química que, mais tarde, foram transferidos para outros campos de experimentação como as ciências sociais. Por conseguinte, compete à ciência romper com uma visão onde predominam o absolutismo filosófico e o relativismo, na medida em que: "mesmo hoje, ao falarmos da teoria da ciência, falamos de 'ciência' e de 'método' científico, como se houvesse uma ciência e um método científico - ideia tão quiméricas como a antiga noção de que só havia uma cura para todas as doenças" (Elias, 2008: 57).

Assim, o autor questiona como e em que condições é possível o conhecimento nãoideológico e científico de relações naturais e sociais. Este não se encontra ainda clarificado, incluindo para os próprios sociólogos, no que diz respeito ao modo como as teorias sociológicas diferem das ideologias sociais e se existe de facto tal diferenciação. As atitudes de um investigador e os seus critérios científicos são em grande medida modelados por considerações extra científicas quer políticas, quer religiosas, quer de profissão. É certo que o autor assume uma postura prudente ao afirmar que "nenhum método científico poderá garantir em si próprio a validade de todos os resultados obtidos pela sua aplicação" (2008: 65). Igualmente, Weber (1977 [1904]) nos elucidou acerca dos limites da investigação em sociologia, afi rmando que esta é válida para um período e um espaço social determinados, não constituindo "leis gerais" no sentido das ciências ditas exactas. 0 mesmo nos diz Passeron (cit in Marques, 2006) que perspectiva a história das ciências sociais constituída por "teorias interpretativas", por "saberes empírico relacionais", por raciocínios que se desenvolvem num "espaço assertivo não popperniano" no sentido que não é regido pela "prova" dos empiristas lógicos. Por sua vez, Bourdieu (2005) reforça o trabalho de "auto -sócio análise" no ofício do sociólogo, o que implica que se avance para uma sociologia da sociologia próxima de uma sociologia reflexiva. 


\subsection{Para além de um modelo burocrático e de especialização disciplinar}

33 No desenvolvimento da argumentação de Elias tem lugar relevante a sua oposição ao modelo de organização burocrático e racional e à excessiva especialização disciplinar dos tempos contemporâneos, por se tratar de um paradigma que "mata" e anula as interdependências e as emoções unificadoras do "eu" e do "nós". Neste contexto, a sociologia corre o risco de se fragmentar em sociologias cada vez mais especializadas como, por exemplo, a da família, das organizações, do crime, da arte, sendo que "haverá especialistas em todos estes campos, elaborando os seus próprios termos técnicos, as suas teorias e métodos que se tornarão inacessíveis aos não especialistas. Terão então realizado o ideal básico do profissionalismo - a autonomia absoluta das novas especializações. A fortaleza estará completa, as pontes levadiças erguidas" (Elias, 2008: 53).

Este processo repete -se ao longo da evolução das actuais ciências sociais, como a psicologia, a antropologia, a economia, o serviço social, entre outras. A especialização do conhecimento tem aumentado tanto que estamos numa posição que melhor permite compreender o alcance dos problemas decorrentes de uma ciência especializada. Elias relaciona este facto com a necessidade de se ligarem as várias áreas disciplinares, constatando a relação que existe entre diversos domínios desde o físico, o químico e o biológico. $O$ autor põe a tónica na importância de uma compreensão gradual e crescente de todos os domínios. Diz -nos: "a especialização científica é actualmente tão rigorosa que a inclusão na consideração das características universais da sociedade de problemas que envolvem as pessoas no singular e no plural aparece quase como uma ilegalidade, uma infracção de fronteiras ou mesmo como uma alteração das linhas de demarcação" (Elias, 2008:14).

Para além do questionamento que faz acerca das especializações, com consequências na fragmentação e nas dinâmicas das interconexões sociais, outro ponto fulcral da sua análise crítica da organização social prende -se com a "abordagem objectiva", "racional" e "realista" em que os governantes acreditam para ultrapassar os problemas sociais mais prementes, designada por burocracia. Elias critica o pensamento Weberiano ${ }^{5}$ em que fundamenta a burocracia contemporânea como uma forma racional de organização. $\mathrm{Na}$ esteira de Elias (2008: 2008), a burocracia "tende hoje a reduzir as interdependências sociais complexas a departamentos administrativos singulares; cada um deles tem a sua área de jurisdição estritamente definida, sendo equipados com uma hierarquia de especialistas e uma oligarquia de chefes administrativos, que raramente pensam para além da sua área de competência".

Deste pensamento de Elias depreende-se que uma outra proposta se pode configurar oposta à da de burocracia que se apresenta estático e compartimentado: um modelo organizacional, dinâmico, aberto a alterações. Esta visão pode configurar o desenho de um modelo com contornos semelhantes ao modelo actualmente designado de organização em rede, policêntrico, heterárquico ou reticular, por conter dimensões como a interdependência entre os actores, a flexibilidade na gestão, a aç̧ão dinâmica nas (re)configurações criadas pelo processo de auto-transformação gerado continuamente.

Neste sentido, Elias considera que o desenvolvimento das sociedades, aos olhos dos seus executores (cargos governamentais e seus ajudantes), tende a aparecer como um 
problema "económico". o foco está em aumentar o potencial económico das sociedades estados mais pobres, aumentando o stock de capitais. São construídas centrais de energia, estradas, pontes, caminhos-de-ferro, fábricas e é impulsionada a produção agrícola. A este respeito afi rma, “quando o desenvolvimento 'económico' é assim impulsionado, tendo como objectivo limitado o melhoramento do nível de vida, torna -se evidente que é impossível desenvolver o potencial económico sem que haja uma transformação total da sociedade" (2008:160). O autor explica que planos puramente económicos podem falhar, uma vez que outros aspectos não económicos, mas funcionalmente interdependentes de uma sociedade, atuam como freio empurrando-os em direcção contrária.

o processo global de desenvolvimento de uma sociedade, embora não planeado e não imediatamente controlável, não é, para o autor, incompreensível. o que está em causa são as consequências decorrentes da interpretação das acções de inúmeras pessoas interdependentes, já que ninguém pode determinar o decurso do jogo porque não actua sozinho. Os acontecimentos e os factos originam -se do fluxo contínuo da acção individual imersa nos contextos de interacção social. Este processo implica uma mudança "parcialmente auto-regulada numa confi guração de pessoas parcialmente auto organizada e auto-reprodutora, tendendo o processo para uma certa direcção" (Elias, 2008:161). Na esteira do autor, as hipóteses teóricas dominantes pendem para considerar "normal" o facto de uma sociedade se manter no estado que atingiu. A questão que se afigura mais desconcertante, no que respeita ao desenvolvimento, é o facto dos nossos esforços se dirigirem menos para a compreensão e explicação daquilo que realmente acontece e para a elaboração de um diagnóstico do que para a "elaboração de um esperançoso prognóstico" (2008: 162).

\section{O pensamento da complexidade e a organização em rede}

A rede, ou estrutura policêntrica, objecto deste artigo, é aquela que se apresenta como um projecto deliberado de organização da acção humana. A rede pode ser concebida como um padrão organizativo que ajuda os actores sociais a empreenderem, a obterem resultados a partir de modelos de acção horizontais, não hierárquicos, que visam a transformação da realidade. Não obstante, o pensamento Eliano não ignora existência de relações hierárquicas, verticais, de dominação e poder nas confi gurações geradas nas interdependências das relações sociais (Silva, 1998).

\subsection{Riscos, (inter)acções e parcerias na actualidade}

Na base de multiplicação das estruturas policêntricas está a transformação da sociedade contemporânea. Na "sociedade de risco" (Beck, 1992), caracterizada pela incerteza e insegurança, o cidadão já não pode contar com as tradições e os sistemas sociais herdados da sociedade industrial. Estes não se encontram ajustados e capazes de responder às novas realidades económicas, culturais e sociais. Em alternativa, "a noção de risco tornase central numa sociedade que se está a despedir do passado, dos modos tradicionais de fazer as coisas e que se está a abrir para um futuro problemático" (Giddens, 1997:103). Igualmente, a reflexividade social constitui uma forma de gerir melhor a dubiedade constante, ao reivindicar o pensamento em profundidade sobre as circunstâncias em que se vive e a capacidade de se "controlar" o futuro. 
41 Anteriormente vivia -se um mundo assente no costume e na tradição, não exigindo, por isso, uma necessidade tão apurada de reflexão, pois aspectos essenciais da vida eram ponto assente, estavam seguros. Hoje não é assim. Atento ao contexto da complexidade, Morin afirma (1997:67): “o esforço da reflexão é vital, mas é pena que nada a ensina... reflectir é tentar compreender... ver qual pode ser o sentido, quais podem ser as perspectivas. Mais uma vez, para mim a linha de força de uma sabedoria moderna seria a compreensão". Também Castells (1999:1) compreendeu que "um novo mundo está tomando forma neste fim de milénio" e baseia a sua perspectiva nas mudanças ocorridas a partir do final dos anos 60 e meados da década de 70 considerando a coincidência histórica de três processos: $i$ ) revolução da tecnologia da informação; ii) crise económica do capitalismo e do estatismo e a reestruturação de ambos; iii) e apogeu de movimentos sociais e culturais. Assim, “a interação entre esses processos e as reações por eles desencadeadas fizeram surgir uma nova estrutura social dominante, a sociedade em rede; uma nova economia, a economia informacional/global; e uma nova cultura, a cultura da virtualidade real. A lógica inserida nessa economia, nessa sociedade e nessa cultura está subjacente à ação e às instituições sociais num mundo interdependente" (Ibidem). Da análise do pensamento do autor, assume relevância a dinâmica gerada pela complexificação dos processos, activadora da interdependência. Por conseguinte, o crescente recurso à (inter)acção surge como estratégia para enfrentar um ambiente de turbulência, de forte competitividade, de reestruturações na esfera pública e nas organizações do mercado e, ainda, de crise do Welfare State. Estas condições abrem espaço para a emergência de novas formas de organização da acção pública e do mercado. As transformações em torno do papel do Estado e da concepção de políticas públicas têm contribuído para uma diversidade de estudos e enfoques teóricos, visível nas seguintes definições, entre outras, de "Estado heterogéneo" (Santos, 1994), "Estado labiríntico" (Ruivo, 2000), "Estado avaliador" (Henkel, 1991), "Estado animador" (Donzelot e Estèbe, 1994), "Estado sábio" (Massardier, 1996), "Estado parceiro" (Schweyer, 1996)․

No contexto de gestão dos problemas da actualidade, Geddes (2000) atesta a ideia de que a acção pública no contexto europeu se encontra marcada pelo surgimento de novos padrões de desemprego, pobreza e privação, surgindo a parceria local, na década de noventa, como parte integrante da reestruturação dos padrões de governança europeia. As parcerias são vistas como uma forma mais flexível de "governança em rede" (in Geddes, 2000:2) por se considerar serem capazes de resolver alguns dos problemas enfrentados pelo Estado, de encontrarem novas soluções para os problemas de uma política complexa, de partilha de riscos e de construção de confiança entre vários públicos e sectores da comunidade.

43 A reconfiguração do papel do Estado tem favorecido a proliferação de redes gestoras de políticas públicas, com forte incidência no sector social. As redes têm sido vistas como a solução para gerir políticas e projectos de intervenção dada a complexidade dos problemas, a escassez de recursos, a multiplicidade de actores envolvidos, a interacção de organizações públicas e privadas, centrais e locais (Teixeira, 2002). Este contexto cria condições para a implementação de um modelo de governança que "pressupõe uma reconfiguração das relações entre o Estado, o mercado e a sociedade civil no sentido do estabelecimento de redes e parcerias efectivadas por uma crescente participação dos actores da sociedade civil" (Neves et al., 2010:15). A acção local acontece neste contexto como resposta possível não só a problemas sociais e económicos, como também ao peso burocrático do Estado. Constitui, ainda, por um lado, uma forma de resistência à 
degradação dos direitos sociais e, por outro, de consciência social orientada para a mudança (Rodrigues e Stoer, 1994). A acção local exige a participação da comunidade local, tendo para isso como seus principais actores, desde grupos comunitários a movimentos sociais e associações locais, a empresas, igrejas e instituições públicas (Neves et al., 2010). Tomando Klein (2005) como referência, a acção local constitui fonte de desenvolvimento local quando gera ou reforça dinâmicas sistémicas locais.

Uma crescente consciência cidadã reclama maior participação, o que vem reforçar a crescente multiplicação de redes. Contrariamente ao modelo de Estado tradicional burocrático, rígido e hierarquizado que impede acções articuladas, as redes surgem como organizações horizontalizadas e flexíveis de diversos agentes sociais (Sotero, 2006). A organização em rede implica uma nova abordagem quanto aos processos de decisão, planeamento e avaliação, considerando três dimensões fundamentais que a caracterizam: risco, interdependência e aprendizagem (Areias, 2007).

\subsection{Portugal, contexto potenciador de organização em rede?}

Associada a esta perspectiva global do contexto que se vive na actualidade, em Portugal desconhecem-se estudos de caso que possibilitem um conhecimento aprofundado acerca deste fenómeno, de modo a compreender se há outras e melhores formas de organização distintas da administração clássica para uma intervenção geradora de mudança.

Abordamos o contexto português visto pelo filósofo José Gil (2008), para melhor nos situarmos no espaço em que agimos e desse modo desenvolvermos reflexão, sentido crítico, compreensão e clareza sobre nós próprios e o nosso contexto. Gil, de forma peremptória, afirma (2008:37): "Numa palavra, o Portugal democrático de hoje é ainda uma sociedade de medo. É o medo que impede a crítica. Vivemos numa sociedade sem espírito crítico". Este pensamento, revelando o peso dos factores culturais e simbólicos da sociedade portuguesa, é importante para se compreender as formas de organização em rede. Na verdade, o filósofo acrescenta que também o queixume e a conformidade, associados à indiferença com aquilo que nos rodeia, fomentada pelo fenómeno da "não inscrição", isto é, a acção de que tudo que acontece não transforma o real, dito de outra forma, não surte nenhum efeito, caracterizam o Portugal de hoje. $O$ autor fala da importância da investigação e do avanço no domínio científico, sendo essencial para que tal aconteça, a discussão, a troca de ideias, a imaginação sem entraves, a elaboração livre de modelos. Neste domínio, Gil refere "a falta de uma comunidade científica que se imponha à comunidade em geral", dado que "o eco dos trabalhos académicos não ultrapassa os círculos especializados, não existindo planos mediadores que levem esses conhecimentos até ao homem comum..." (Gil, 2008:35). Alerta, por conseguinte, para a necessidade da inconformidade, para dessa forma se transformar o país num conjunto de cidades inteligentes, dotadas de cultura, pensamento próprio, livres e independentes. Em obra posterior, Gil vai mais longe na reflexão, considerando que o verdadeiro problema de Portugal reside na sua identidade, que constitui a "raiz dos nossos medos, da paralisia perante a acção, da recusa da mudança. Viriam daí as nossas incapacidades de nos transformarmos...?" (Gil, 2009: 9).

Este pensamento transporta -nos para um a necessidade de questionarmos até que ponto o contexto em que vivemos é favorecedor; se é estimulante para a emergência de intervenções criativas com os riscos que lhe estão inerentes; se a dúvida é um incentivo para a acção ou se, pelo contrário, gera um medo que paralisa a procura de alternativas de 
mudança. De que confiança precisamos? Em que medida Portugal apresenta um contexto que favorece a intervenção organizada em forma de rede interorganizacional? Ou seja, as características organizacionais de uma rede interorganizacional detêm um perfil adequável ao contexto cultural e social em que vivemos?

\subsection{Organização em rede: para lá de uma "cultura" burocrática} comunicação, coordenação e controle tornou -se uma espécie de segunda natureza" (Capra, 2002:115). De acordo com o mesmo autor, a adopção dessa perspectiva, de forma praticamente inconsciente, tornou-se um dos principais obstáculos que se intromete no caminho de qualquer que seja os projectos ou necessidades de mudanças ou desenvolvimento sentidas por parte das organizações, sejam públicas ou privadas. 0 predomínio de organizações fechadas, com serviços sem articulação entre si suportados em esquemas de decisão fortemente hierarquizados e sem estimular a iniciativa, conduzira à necessidade de se proceder à sua reestruturação e reforma, à procura de alternativas organizacionais e gestionárias ${ }^{8}$. Neste contexto, como salienta Sotero (2002), o conceito de rede tem estado associado a novas formas de organização e gestão do trabalho como resultado do questionamento da eficácia das estruturas burocráticas e verticais, fazendo emergir formas mais interactivas e horizontais nos modelos organizativos da gestão das organizações e políticas públicas. Acrescenta, ainda, que as redes rompem com o desenho hierarquizado e rígido da burocracia do Estado tradicional e surgem como organizações horizontalizadas e fl exíveis de diversos agentes sociais.

\section{Algumas notas finais} mudança dos padrões com que nos habituamos a conviver. O que está em causa é a forma como se pensam as coisas. Pensar é a condição indispensável para qualquer análise sobre a realidade e pensar com coerência exige um referencial de conceitos articulados entre si 
competentes para a compreensão rigorosa da realidade. Foi nesse sentido que revisitamos o pensamento de Norbert Elias.

Assim, a partir da análise da obra de Norbert Elias, descobriram -se constructos para compreender a complexidade da contemporaneidade e os "novos" modelos organizacionais, as formas de organização em rede, que dela emergem. Logo numa primeira análise, três pontos relevantes se entrelaçam: $i$ ) uma visão universalista, que procura uma ligação interdisciplinar entre as ciências; ii) uma perspectiva dinâmica e interdependente dos processos sociais; iii) uma dimensão histórica na abordagem dos problemas sociais.

Elias apropria conhecimentos provenientes de áreas vistas com "desconfiança", pela tradição sociológica, entre outras, a biologia, a psicologia cognitiva e as designadas neurociências. Propõe que a sociologia rompa com a noção de autonomia absoluta da ciência para uma concepção de autonomia relativa, uma vez que o ser humano, na medida em que se relaciona com os outros, externaliza as suas dimensões biológica e psicológica. A sua leitura da realidade confere-lhe uma visão "total" do fenómeno humano e para o qual diversos saberes são convocados para o domínio do conhecimento sociológico. 0 autor rompe com a perspectiva epistemológica da modernidade de fragmentação do conhecimento por disciplinas, já que ele próprio foi possuidor de uma formação em várias áreas do saber que lhe permitiram perceber a importância das interdependências, não cabendo nesse pensamento a divisão disciplinar. A concepção teórica e metodológica de Elias apresenta, por conseguinte, um carácter dinâmico, que valida o entendimento sobre as configurações societais que se constroem a partir das interdependências num processo dinâmico de permanente interacção desencadeado no espaço empírico.

Elias produz uma exaustiva análise da relação "indivíduo-sociedade" encontrando uma resposta alternativa a esta noção reinterprendo-a à luz da relação "nós - eu", isto porque, na sua perspectiva, o que falta são modelos conceptuais e uma visão global que os torne compreensíveis. $\mathrm{O}$ autor apela à relação entre a parte e o todo, tentando compreender as forças sociais a que os indivíduos estão sujeitos e explicando que tais forças sociais são exercidas pelas pessoas sobre outras pessoas e também sobre si próprias.

Palavras como interdependência, relação, rede e teia são centrais no pensamento Eliano e dão lugar a uma teoria central da sociologia que se aproxima da empiria e proporciona fundamento teórico à construção de um alicerce para refutar, corrigir e transformar a compreensão das configurações do viver no mundo. Uma constante do pensamento do autor é a convicção de que "o homem é obra do próprio homem" e a rede de interdependências é o que os liga, formando elas o nexo do que ele designa por configurações, isto é, o conjunto de pessoas mutuamente dependentes. Por isso, refuta as polarizações clássicas entre abordagens individualistas e holistas, causalistas e dualistas. Além disso, cria um paradigma que une estas perspectivas opostas através de um quadro de inteligibilidade sobre as sociedades complexas e paradoxais, abertas à criação e recriação de formas organizacionais, resultado da necessidade de se criarem abordagens inovadoras com maior potencial de adaptação a um ambiente turbulento e em mudança e mais harmonizados com processos de auto-transformação continua. Falamos das formas de organização em rede, baseadas na interdependência, risco e aprendizagem tão necessárias para se analisar e compreender as actuais tendências de configuração societal. Estas formas de organização em rede constituem modelos opostos ao clássico de organização definido como fechado, hierárquico e burocrático. 

reticulares da contemporaneidade é a importância que Elias atribui ao "resultado": para ele o que importa é o que sobressai a partir da dinâmica social. No entanto, na nossa perspectiva, algumas questões ficam por esclarecer do pensamento do autor: Qual a natureza dos conflitos na sociedade actual? De que forma os conflitos se relacionam com a noção "nós-eu" ou na perspectiva tradicional “ indivíduo -sociedade"? Para terminar, é necessário realçar que a sociedade de indivíduos é construída na teia da rede das interdependências das relações sociais geradora de "fenómenos reticulares", dito de outra forma, o indivíduo em sociedade é uma "rede" criadora de fenómenos reticulares através das relações de interdependência num processo originador de (re)configurações constantes. $O$ conceito de rede na visão Eliana centra-se nos processos interactivos das relações.

Através da problematização que desenvolve é evidenciado que a relação entre indivíduo e sociedade só pode ser compreendida através da multidimensionalidade das relações sociais. A complexa teia de redes, construída num processo contínuo e dinâmico, é geradora de mudanças permanentes, em que todos os indivíduos são encarados como participantes, delineadores (em diferentes graus) e com potencial de operar transformação na sociedade.

\section{BIBLIOGRAPHY}

AREIAS, Helena (2007), Desenvolvimento Local e Rede Social: Moda ou Modelo de Intervenção? Tese de Mestrado em Desenvolvimento, Diversidades Locais e Desafi os Mundiais, Instituto de Ciências do Trabalho e da Empresa (ISCTE) Lisboa (policopiado).

BECK, Ulrich (1992), Risk Society towards a New Modernity, London: Sage.

BOURDIEU, Pierre (2005), Esboço para uma auto-análise, Lisboa, Edições 70.

CASTELLS, Manuel (1996), A Sociedade em Rede - A Era da informação: Economia, Sociedade e Cultura, Vol I, Lisboa: Fundação Calouste Gulbenkian.

CASTELLS, Manuel (1999) A Era da Informação: economia, sociedade e cultura, vol. 3, São Paulo: Paz e Terra. pp $411-439$.

CAPRA, Fritjof (2002), As conexões ocultas, São Paulo: Cultix.Amana -Key.

COSTA, Larissa. et al. (org) (2003), Redes - Uma Introdução às Dinâmicas da Conectividade e da Auto Organização, Rebeca Kritisch (WWW -Brasil).

DABAS, Elina (2001), Redes Sociales: Nivel de Abordaje en la Intervencion y Organizacion en Red [disponible e http://www.santafe.gov.ar/index.php/web/content/download/71292/345905/fi le/ Redes\%20Sociales.pdf]

DONZELOT, Jacques; ESTÈBE, Philippe (1994), L'Etat Animateur. Essai sur la Politique de la Ville, Paris: Esprit.

ELIAS, Norbert (2008) [1970]), Introdução à Sociologia, Lisboa: Edições 70. 
ELIAS, Norbert (2004 [1987]), A Sociedade dos Indivíduos: «A questão cardeal da sociologia», Lisboa: Publicações Dom Quixote.

ELIAS, Norbert (1989) [1939]), O Processo Civilizacional, Vol. I., II., Lisboa: Publicações Dom Quixote.

ELIAS, Norbert (2001) [1990]), Nobert Elias, por ele mesmo, Rio de Janeiro: Jorge Zahar Editor.

FAYOL, Henri (1990), Administração Industrial e Geral, 10, Ed. São Paulo: Atlas.

GEDDES, Mike (2000),"Tackling Social Exclusion in the European Union? The Limits to the New Orthodoxy of Local Partnership", International Journal of Urban Regional Research Volume e 24,4.

GIDDENS, Anthony (1997), Modernidade e Identidade Pessoal, Lisboa: Celta Editora.

GIL, José (2008), Portugal, Hoje - O Medo de Existir, Lisboa: Relógio D’Águ Editores.

GIL, José (2009), Em Busca da Identidade, Lisboa: Relógio D’Água Editores.

HENKEL, M. (1991), “The new evaluative state”, Public Administration, 69, pp. 121 -136.

KLEIN, Juan Luis (2005), “Iniciativa local y desarrollo: respuesta social a la globalización neo liberal”, Revista Eure, XXXI, pp 25 -39.

LANDINI, Tatiana S. (2005), "A sociologia processual de Norbert Elias”, in IX Simpósio Internacional Processo Civilizador - Tecnologia e Civilização. Ponta Grossa - Paraná: Anais do IX Simpósio Internacional Processo Civilizador.

LIPNACK, Jessica e STAMPS, Jeffrey (1994), The Age of Network: Organizing Principles for the 21st century, England: Omneo (Essex junction, vt).

MARQUES, Ana Paula (2008), Estudo Prospectivo sobre Emprego e Formação na Administração Local, col. «Estudos CEFA», Coimbra: CEFA.

MARQUES, Ana Paula (2007), Relatório Final do projecto de investigação MeIntegra - Mercadose estratégias de inserção profissional. Licenciados versus empresas da Região Norte, Centro de Investigação de Investigação em Ciências Sociais da Universidade do Minho (policopiado).

MARQUES, Ana Paula (2006), Entre o Diploma e o Emprego. A inserção profi ssional de jovens engenheiros , Porto, Afrontamento, Porto, Editora Afrontamento/ NES.

MASSARDIER, Gilles (1996), Expertise et Aménagement du Territoire. L'Etat Savant, Paris:

L'Harmattan.

MENNELL, Stephen (1998), Norbert Elias - An Introduction, Dublin University College Dublin Press.

MILES, Raymond e SNOW, Charles (1992), “Causes of failure in Network organizations”, in California Management Review, Vol. 34, no 4, pp. 53 -72.

MORIN, Edgar (1973), O Paradigma Perdido, Mem Martins: Publicações Europa-América.

MORIN, Edgar (1997), Amor Poesia Sabedoria, Lisboa, Instituto Piaget.

MORIN, Edgar (2008), Introdução ao Pensamento Complexo, Lisboa, Instituto Piaget.

NEVES, Tiago et al. (coord) (2010), Acção Local No Combate à Pobreza e Exclusão Social, Porto: Legis editora.

NOGUEIRA, J. (2004), “Network forms of organization: a cock and bull tale?”, in Periploi Working papers, $\mathrm{n}$ ”008,Lisboa: Instituto de Investigação Aplicada.

PRIGOGINE, Ilya (2000), “The Network Society”, Journal of World -Systems Research, Vol. VI, no, pp. $892-89$

PRIGOGINE, Ilya (1996), o Fim das Certezas, Lisboa: Gradiva. 
RODRIGUES, Fernanda; STOER, Stephen (1994), A acção local e cidadania. Dinâmicas Culturais, Cidadania e Desenvolvimento Local, Lisboa: Associação Portuguesa de Sociologia.

RUIVO, Fernando (2000), O Estado Labiríntico. O Poder Relacional entre Poderes Local e Central em Portugal. Porto: Afrontamento.

SANTOS, Boaventura Sousa (1994), Pela Mão de Alice. O Social e o Político na Pós -modernidade, Porto: Afrontamento.

SARMENTO, Jacinto Manuel; MARQUES, Ana Paula; FERREIRA, Fernando Ilídio (2009), Administração Local. Políticas e Práticas de Formação, Braga: BragaBooks/ Universidade do Minho.

SÉGUIN e J. -Francine CHANLAT, François (1983), L'analyse des organisations. Une anthologie sociologique, Tome I - Les Théories de l'organisation, Montréal, Gaetan Morin Éditeur.

SILVA, Manuel Carlos (1998), Resistir e adaptar -se. Constrangimentos e estratégias camponesas no noroeste de Portugal, Porto: Afrontamento.

SOTERO, F. (2002), “Gestão Participativa em Rede - GPR: Descentralização e Participação na Gestão Municipa", in VII Congresso Internacional do CLAD Centro Latinoamericano de Administração para o desenvolvimento sobre a Reforma do Estado e da Administração Pública, Lisboa (policopiado).

SCHWEYER, F. -X. (1996), “Vers un État partenaire?” in S. Paugam (dir.), L'Exclusion. L'état des Savoirs, Paris: La Découverte, pp. 487 -506.

TEIXEIRA, Sonia (2002), “O desafi o da gestão das redes de políticas", in VII Congresso Internacional del CLAD sobre Reforma del Estado y de la Administración Pública, Lisboa (polocopiado).

WEBER, Max (1977 [1904]), Sobre a Teoria das Ciências Sociais, Lisboa: Ed. Presença.

\section{NOTES}

1. Neste artigo serão alvo de revisitação várias obras publicadas de Nobert Elias (2008 [1970], 2004 [1987], 2001 [1990], 1989 [1939]).

2. Para Elias (2004), homo clausus significa homem fechado em si mesmo. Esta concepção não decorre somente de uma visão da sociologia do fi $\mathrm{m}$ de séc. XIX para o séc. XX, já que esteve presente na filosofia ocidental desde a antiguidade, com Platão, e teve grande influência dos filósofos do Renascimento, tais como Descartes, Locke e Kant. Esta visão pode também ser observada em sociólogos como Durkheim (facto social), Weber (no modelo teórico de acção social, mas não no empírico) e Parsons (os processos ocorrem dentro da caixa preta) (Mennel 1998).

3. Há uma grande discussão entre os estudiosos de Elias sobre a utilização do termo figuração ou configuração. $O$ autor utilizou ambos os termos, muito embora em grande parte da sua obra usasse o termo "configuração" para fazer face ao termo "sistema" usado por Parsons, autor que Elias (2004) tanto criticou.

4. A este propósito, note-se que tradicionalmente a sociologia refuta qualquer contacto com a biologia, com receio, supostamente, da naturalização decorrente da análise dos fenómenos sociais.

5. Weber (1995 [1921]) desenvolve o primeiro grande modelo de organização racional que se caracteriza por um conjunto de traços que persiste até hoje: i) predomínio de regras fixas e impessoais ao nível dos procedimentos e de execução, sendo que estas se encontram suportadas em documentos escritos (e.g. regulamentos, estatutos, manuais); ii) hierarquia de funções que clarifica a linha de decisão e delimita as responsabilidades associadas; iii) desempenhos profissionais de cariz técnico e especializado, exigindo-se uma formação dos trabalhadores. Resultam desta lógica impessoal e fixa, independentemente das pessoas, dos serviços ou dos 
contextos, vantagens claras deste modelo que se prendem com a continuidade, a impessoalidade e a imparcialidade.

6. Apesar desta diversidade teórico-empírica, poder -se -á argumentar que aquelas propostas apresentam em comum "novas formas de acção estatal, lembrando que o essencial da análise não é o Estado, enquanto entidade abstracta, mas antes as práticas e os processos de governação, nos quais participam, juntamente com o Estado e os seus aparelhos institucionais, organizações, associações de carácter social e cultural, especialistas em diversos domínios, serviços centrais e regionais da administração, inspecção, institutos, entre outros" (Sarmento, Marques e Ferreira, 2008:17).

7. Weber, numa perspectiva crítica dos limites desta concepção, preocupou -se com as consequências da burocracia para o lado humano da sociedade, reconhecendo-lhe potencial para rotinizar e mecanizar a vida humana, corroendo o espírito de acção espontânea e minando as formas democráticas de organização. $\mathrm{Na}$ verdade, esta a teoria intimamente ligada a Weber assume, para muita gente, uma conotação negativa por estar associada ao excesso de papéis e de regras prejudicando o funcionamento eficaz e inovador das organizações. Não obstante, no pensamento weberiano, este modelo de organização de cariz burocrático potenciaria um tratamento equitativo de todos os empregados, uma vez que a cada um deles eram atribuídas áreas específi cas de responsabilidade e acção na base das suas competências e capacidades.

8. Tal torna -se mais premente num contexto de crise económica, de liberalização e globalização dos mercados e de movimentos de privatização de certos serviços públicos (Marques, 2008).

\section{ABSTRACTS}

A organização em rede, morfologia característica da sociedade actual, é motivada em parte pela crítica a modelos organizacionais desadequados ao contexto societal e económico em que se vive. Novas formas organizacionais surgem como as estruturas policêntricas ou em rede, que visam gerir as mudanças que ocorrem a uma velocidade sem precedentes. Para este processo de reconfiguração organizacional convoca-se o pensamento Eliano pela actualidade do seu contributo para a compreensão de um mundo complexo, paradoxal, com inclusão de dimensões de incerteza e risco. Para Norbert Elias as relações sociais são explicadas não só pela estrutura como pela perspectiva de rede como uma teia de complexas interdependências criada pelas interacções humanas entre o"eu" e o "tu”, entre o "nós" e o "eles", entre indivíduos diferentes e/ ou iguais, em constante dinâmica geradora de fenómenos reticulares. $\mathrm{O}$ argumento central deste artigo desenvolve -se primeiro através da revisitação do pensamento de Elias para, em seguida, questionar o conhecimento acumulado sobre o pensamento em rede nas Ciências Sociais de modo a se posicionar uma alternativa crítica para lá da lógica da racionalidade linear, causal e determinista.

Network organization, which is the morphological characteristic of the current society, has been motivated in part by the criticism of organizational models not suitable for present-day society. New organizational forms have emerged as polycentric and networking structures whose aim is to manage the changes which occur at an unprecedented speed. For the organizational reconfiguration process, the thoughts of Norbert Elias are presented due to their pertinent contribution for the understanding of a complex and paradoxical world with uncertainty and risk. According to Norbert Elias, social relationships are explained by the network perspective 
formed by complex interdependencies created by human interactions in a permanent dynamic between "self" and "us", equal and/or different individuals which generate reticular phenomena. The central argument of this paper has been primarily developed by way of the revision of Elias's thinking and secondly, by questioning the accumulated knowledge focused on network in social sciences in order to provide a critical alternative beyond the linear logic of casual and deterministic rationality.

Cette étude est une première approximation à l'univers des blogs qui permettent l'accès aux fichiers de musique via internet. Il vise à répondre aux changements dans l'industrie de la musique et du public dans le processus de production de la communication et la participation des jeunes à la création de nouvelles utilisations des ressources des médias. Il est également la fonction de cette étude discuter les moyens de production des lectures analytiques dans cet environnement encore peu examinés.

\section{INDEX}

Mots-clés: réseau, organisation, interdépendance, configuration

Palavras-chave: rede, organização, interdependência, música, cultura

Keywords: network, organization, interdependency

\section{AUTHORS}

\section{HELENA AREIAS}

Assistente Social, Docente da Universidade Católica, helena-areias@sapo.pt

\section{ANA PAULA MARQUES}

Socióloga, Professora no Departamento de Sociologia e Investigadora no Centro de Investigação em Ciências Sociais da Universidade do Minho, amarques@ics.uminho.pt 